\title{
EFEITO DO RECIPIENTE E DO MÉTODO DE SUPERAÇÃO DE DORMÊNCIA NO CRESCIMENTO DE MUDAS DE Schizolobium parahyba (Vell.) S.F. Blake
}

\author{
Clarissa Gusmão Figueiró ${ }^{1}$, Filipe Ferreira Macedo ${ }^{2}$, Lucas de Freitas Fialho ${ }^{3}$, Carlos \\ Miguel Simões da Silva ${ }^{4}$, Welliton Lelis Cândido ${ }^{3}$ \\ ${ }^{1}$ Mestrando em Ciência Florestal, Universidade Federal de Viçosa, Viçosa-MG, \\ Brasil (clarissagfigueiro@gmail.com) \\ ${ }^{2}$ Graduando em Ciência Florestal, Universidade Federal de Viçosa, Viçosa-MG, \\ Brasil \\ ${ }^{3}$ Mestrando em Ciência Florestal, Universidade Federal de Viçosa, Viçosa-MG, \\ Brasil \\ ${ }^{4}$ Doutorando em Ciência Florestal, Universidade Federal de Viçosa, Viçosa-MG, \\ Brasil
}
Recebido em: 08/04/2017 - Aprovado em: 10/06/2017 - Publicado em: 20/06/2017 DOI: 10.18677/EnciBio_2017A45

\begin{abstract}
RESUMO
A utilização de mudas com altos índices de desenvolvimento e de sobrevivência é indispensável para o sucesso da implantação de projetos de reflorestamento em áreas degradadas. Para tal, são necessárias as escolhas criteriosas das espécies mais aptas a cada projeto e a produção de mudas em condições adequadas de desenvolvimento. Com isso, o presente estudo teve como objetivo avaliar o desenvolvimento em viveiros de mudas do guapuruvu (Schizolobium parahyba) em função do tipo de recipiente e do método de quebra de dormência. A espécie foi cultivada em quatro tipos comerciais de recipientes para mudas com capacidade volumétrica aproximada de $300 \mathrm{~cm}^{3}, 110 \mathrm{~cm}^{3}$ e $50 \mathrm{~cm}^{3}$. Foram avaliadas duas metodologias de superação da impermeabilidade do tegumento, sendo elas o método de imersão em água e escarificação mecânica. Foram avaliados: a altura, diâmetro de coleto, relação parte aérea e raiz e percentagem de germinação de Schizolobium parahyba de acordo os tratamentos. De modo geral, as mudas produzidas em recipientes com volume de $300 \mathrm{~cm}^{3}$ obtiveram maior altura, diâmetro de coleto, relação parte aérea raiz e percentagem de germinação. No que diz respeito a quebra de dormência, o método que se destacou foi a escarificação mecânica. Acredita-se que o maior volume do recipiente proporciona um maior desenvolvimento das raízes, propiciando uma maior exploração e absorção de água e nutrientes. Quanto ao método de superação de dormência, as sementes submetidas ao método de escarificarão obtiveram maior sucesso germinativo devido ao tegumento embrionário ter ficado exposto, resultando assim um contato imediato da água com o embrião.
\end{abstract}

PALAVRAS-CHAVE: Guapuruvu, qualidade, semente 


\title{
EFFECT OF THE CONTAINER AND METHOD OF DETERMINATION OF THE DORMANCY IN THE GROWTH OF MUDS OF Schizolobium parahyba (Vell.) S.F. Blake
}

\begin{abstract}
The use of seedlings with high rates of development and survival is indispensable for the successful implementation of reforestation projects in degraded areas. For this, it is necessary to choose the species most suitable for each project and the production of seedlings under appropriate conditions of development carefully. The objective of this study was to evaluate the development of Guapuruvu seedlings (Schizolobium parahyba) in the nursery of seedlings, as a function of container type and dormancy breaking method. The species was cultivated in four commercial types of containers for seedlings with an approximate volume capacity of $300 \mathrm{~cm}^{3}, 110 \mathrm{~cm}^{3}$, and $50 \mathrm{~cm}^{3}$. Two methodologies of overcoming the impermeability of the integument were evaluated, being they the method of immersion in water and mechanical scarification. Were evalueted height, collection diameter, shoot and root ratio and percentage of Schizolobium parahyba germination according to the treatments. In general, the seedlings produced in containers with a volume of $300 \mathrm{~cm}^{3}$ obtained seedlings with higher height, collection diameter, root shoot ratio and percentage of germination. As for the breakdown of numbness, the method that stood out was the mechanical scarification. It is believed that the larger volume of the container provides a greater development of the roots, providing a greater exploration and absorption of water and nutrients. As for the method of overcoming dormancy, the seeds submitted to the scarification process obtained greater germinative success due to the embryonic integument being exposed, resulting in an immediate contact of the water with the embryo.
\end{abstract}

KYEWORDS: Guapuruvu, quality, seed

\section{INTRODUÇÃO}

O crescente estímulo para a recuperação de áreas degradadas junto aos remanescentes florestais tem gerado uma demanda para implementação de projetos de inserção de espécies arbóreas nativas em plantações agroflorestais, de restauração florestal e de reabilitação de terras degradadas (COSTA, 2015).

No que se refere à recuperação de áreas degradadas, o processo de formação de uma floresta pode transcorrer através da regeneração natural ou artificial. Muitas vezes, a regeneração natural pode processar-se de forma prolongada e incerta, devido a fatores como agressividade e dominância de plantas invasoras, queimadas, baixa fertilidade natural dos solos e o consumo do banco de sementes. Como alternativa, os métodos de regeneração artificial podem contribuir para a taxa de sobrevivência dessas espécies devido a possibilidade desse método poder minimizar os fatores desfavoráveis, acelerando assim a sucessão natural (BROWN \& LUGO, 1994).

Um dos principais métodos de restauração artificial é o plantio de mudas (FERREIRA et al., 2007). Para a produção de tais mudas em viveiros é necessária a atenção de vários fatores que podem influenciar no crescimento e desenvolvimento dessas mudas, como por exemplo, a escolha da espécie, o método de quebra de dormência e dimensões do recipiente (BAO et al., 2014).

A respeito da escolha da espécie a ser implantada, algumas espécies têm ganhado destaque como o guapuruvu (Schizolobium parayba (Vell.) S.F. Blake) no 
âmbito das pesquisas quanto a produção de mudas. O guapuruvu apresenta baixa exigência quanto a fertilidade do solo e apresenta rápido crescimento (CARVALHO, 2005). Essas propriedades conferem a espécie ser potencial para o seu uso na restauração de áreas degradadas.

Cerca de dois terços das espécies arbóreas, possuem algum tipo de dormência. A dormência de sementes é caracterizado pela falta de germinação mesmo em condições favoráveis (umidade, temperatura, luz e oxigênio) para a semente (OLIVEIRA et al., 2012). A dormência faz com que as sementes geminem no periodo mais propício ao seu desenvolvimento, permitindo que as espécies vegetais sobrevivam as condições que dificultem ou impeçam o seu crescimento vegetativo. O guapuruvu (Schizolobium parahyba), por exemplo, apresenta dormência tegumentar, devido a impermeabilidade do tegumento a água (ARALDI \& AMARAL, 1977; PEREIRA et al., 2011).

Além disso, outra etapa primordial é a definição do formato e o volume do recipiente utilizado para o cultivo de mudas. Segundo LISBOA et al. (2012) os recipientes têm efeito significativo no desenvolvimento das mesmas. Segundo esses autores, a escolha correta dos recipientes propicia a contenção adequada de substrato e água para nutrição e suporte ao crescimento das mudas; a proteção das raízes contra a desidratação e danos mecânicos; o desenvolvimento adequado do sistema radicular e, por consequência, da parte área das mudas; e o aumento na sobrevivência e crescimento inicial em campo. Assim, além de critérios econômicos e operacionais, a escolha dos recipientes deve considerar também a sua influência no desenvolvimento das mudas.

Portanto, a investigação sobre mudas a serem utilizadas na restauração de áreas degradadas torna-se fundamental devido ao fornecimento de informações valiosas sobre a sobrevivência no campo, além de otimizar a fabricação de mudas de espécies nativas e reduzir custos atrelados a sua produção. Esses dados são importantes para a implementação de projetos de restauração, que representam um caminho para o uso sustentável dos recursos naturais (COSTA et al., 2015).

Diante do exposto, objetivou-se avaliar o potencial de crescimento de mudas de Guapuruvu em função do tipo de recipiente e do método de quebra de dormência.

\section{MATERIAL E MÉTODOS}

O estudo foi conduzido em condições de ambiente protegido (viveiro) coberto com tela de nylon $50 \%$. As sementes foram fornecidas pelo viveiro da Sociedade de Investigações Florestais (SIF). Foram avaliadas duas metodologias de superação da impermeabilidade do tegumento, sendo elas o método de imersão em água e escarificação mecânica. Para realização do método de imersão em água, as sementes foram submergidas em água fervente $\left(95^{\circ} \mathrm{C}\right)$ durante um minuto. Já o método de escarificação mecânica consistiu no lixamento na porção distal do eixo embrionário das sementes, com lixa número 150, na parte contrária ao hilo, facilitando assim o contato da água com a parte interior do tegumento da semente. Os recipientes testados foram tubetes cilíndricos pretos em volumes de $300 \mathrm{~cm}^{3}, 110$ $\mathrm{cm}^{3}$ e $50 \mathrm{~cm}^{3}$.

Foram avaliados 6 tratamentos, formados pela combinação de dois métodos de superação de dormência (Escarificação mecânica e imersão em água) e três volumes de tubetes $\left(300 \mathrm{~cm}^{3}, 110 \mathrm{~cm}^{3}\right.$ e $\left.50 \mathrm{~cm}^{3}\right)$. As plantas ficaram dimensionadas equidistantes, com espaçamento de $13 \mathrm{~cm}$ para diminuir a concorrência por luz. 
Cada parcela do experimento foi composta por 15 recipientes (repetições).

Para todos os tratamentos foi utilizado um substrato comercial, constituído à base de casca de pinus processada e enriquecida, vermiculita e trufa processada e enriquecida. Para a adubação dos substratos o fertilizante NPK, constituído de ureia, superfosfato simples e cloreto de potássio, nas dosagens de 350,4000 e $200 \mathrm{~g} / \mathrm{m}^{3}$, respectivamente.

A semeadura foi realizada diretamente nos tubetes, na quantidade de apenas 1 semente por tubete, e as amostras foram colocadas em estufa, com irrigação diária. Aos 90 dias após a produção das mudas, foram mensurados o diâmetro do coleto, com paquímetro digital, altura do caule e comprimento da raiz, em centímetros, com régua milimétrica.

Os dados foram submetidos aos testes de Lilliefors e Cochran para testar a normalidade e homogeneidade das variâncias, respectivamente. O experimento foi analisado considerando-se um fatorial completo, com dois métodos de superação de dormência e três volumes de recipientes. Os resultados foram submetidos à análise de variância (ANOVA). Quando estabelecidas diferenças significativas, os tratamentos foram comparados entre si por meio do teste de Tukey, a $5 \%$ de probabilidade.

\section{RESULTADOS E DISCUSSÃO}

Na Figura 1 são apresentados os parâmetros de crescimento de Schizolobium parahyba em função do método de quebra de dormência e do volume de recipiente. Observa-se que houve efeito significativo das duas variáveis nos valores dos parâmetros estudados.

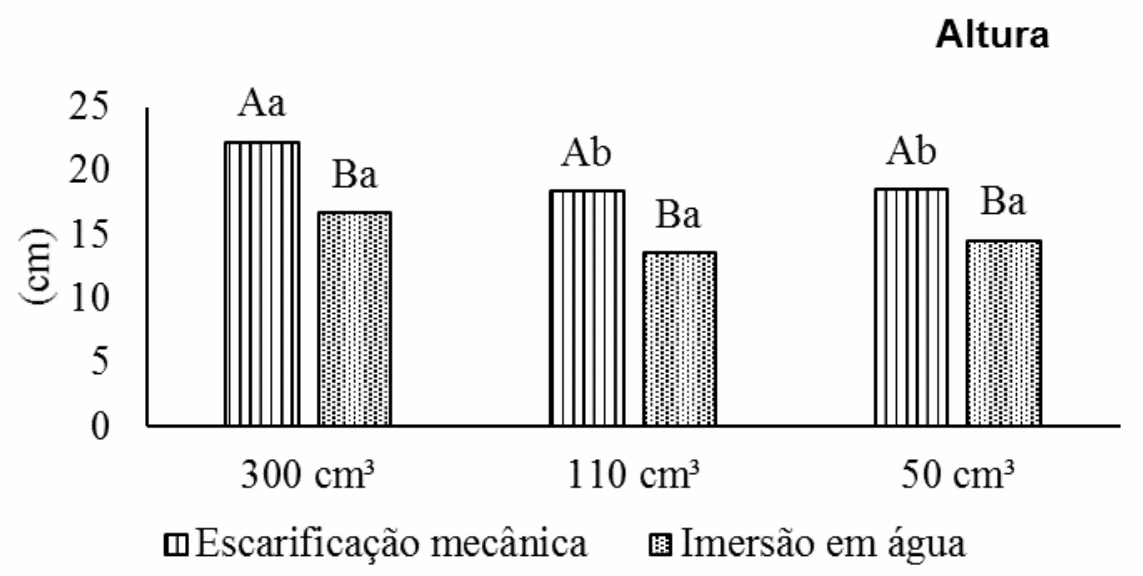




\section{Diâmetro de coleto}

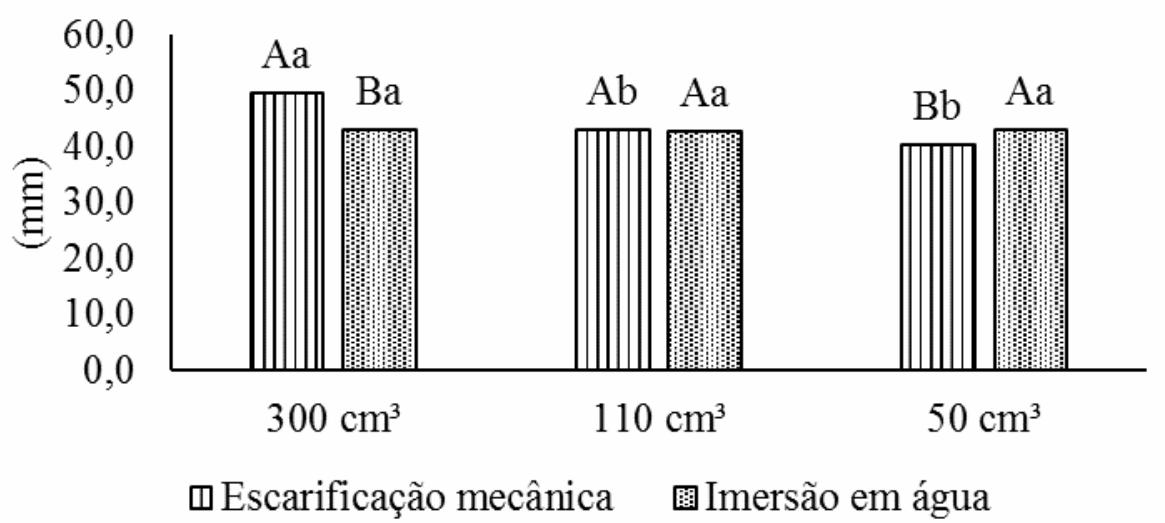

Relação parte aérea e raiz

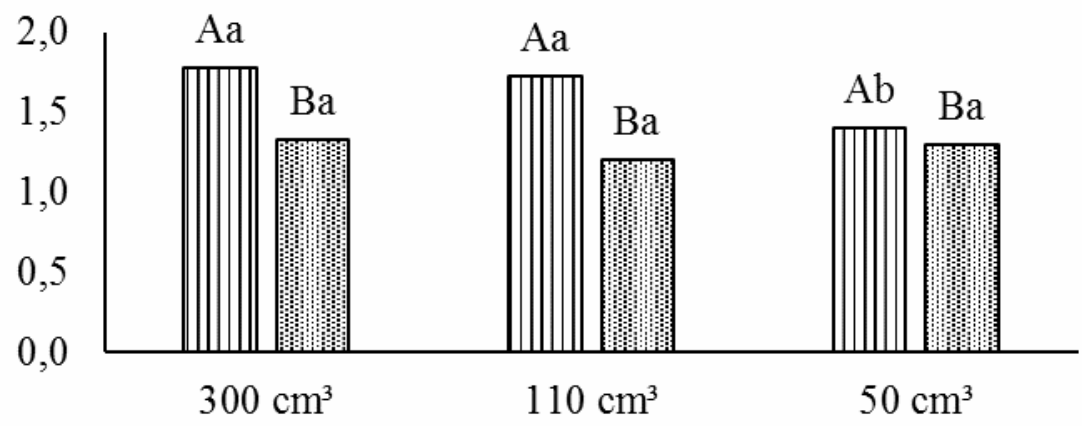

mEscarificação mecânica 固Imersão em água

Percentagem de germinação

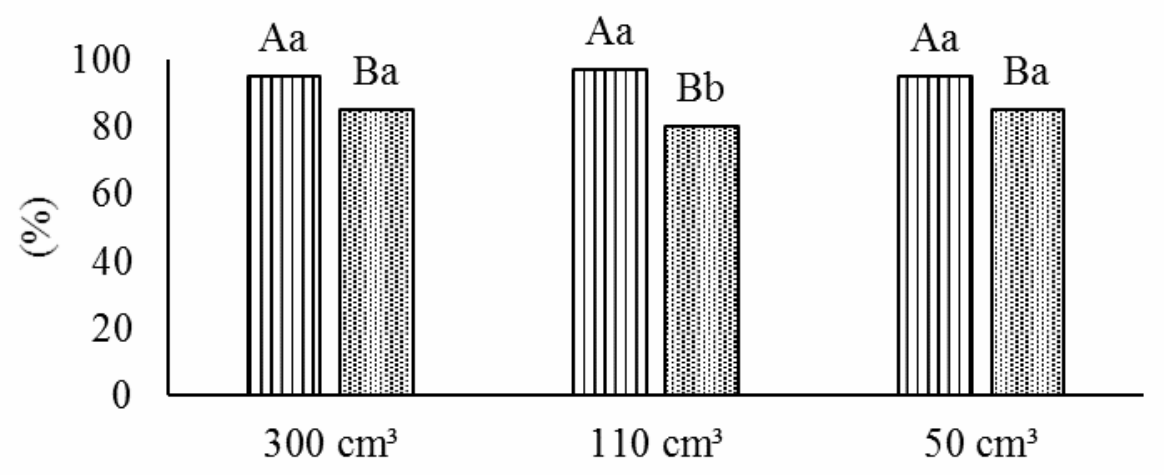

๑Escarificação mecânica 橉Imersão em água

Médias seguidas de mesma letra maiúscula entre volume de tubete e minúscula entre método de quebra de dormência não diferem entre si pelo teste Tukey a 5\% de significância.

FIGURA 1: Altura $(\mathrm{cm})$, diâmetro de coleto $(\mathrm{mm})$, relação parte aérea e raiz e percentagem de germinação (\%) de Schizolobium parahyba de acordo os tratamentos.

De acordo com a figura 1, observa-se que as sementes plantadas no tubete com volume de $300 \mathrm{~cm}^{3}$ obtiveram mudas com maior altura, diâmetro de coleto, 
relação parte aérea raiz e percentagem de germinação. No que diz respeito a quebra de dormência, o método que se destacou foi a escarificação mecânica.

GARCIA \& SOUZA (2015) ao avaliarem aos 120 dias a qualidade de mudas de Schizolobium parahyba em função de diferentes aplicações de adubo fosfatado obteve resultados médios de altura, diâmetro de e relação parte aérea e raiz de respectivamente $21,9 \mathrm{~cm}, 78,0 \mathrm{~cm}$ e 1,6. Ao analisar os valores de diâmetro de coleto, percebe-se que o presente trabalho obteve resultados inferiores aos obtidos por estes autores. Esta diferença é causada devido ao tempo de avaliação das mudas serem diferentes nos dois estudos.

SCHEER et al. (2012) em estudo correlacionaram os parâmetros de crescimento das mudas com a sobrevivência no campo. Segundo os autores, mudas com alturas maiores apresentam maior vigor com o incremento da altura da muda. Além disto, constatou que quanto menor valor obtido na relação parte aérea e raiz, maior será a capacidade de as mudas sobreviverem e se estabelecerem na área de plantio definitivo. Mudas com sistema radicular bem desenvolvido podem apresentam maiores índices de sobrevivência em campo, melhorando a absorção de água e a sustentação da muda no solo.

A respeito das dimensões dos recipientes, as dimensões e características dos recipientes influenciam a arranjo do sistema radicular, afetando assim a disponibilidade e absorção de água e nutrientes, segundo BRACHTVOGEL \& MALAVASI (2010). SIMỖES et al. (2012) relatam que a má-formação do sistema radicular traz um desiquilíbrio na parte aérea, uma vez que impede a absorção necessária de água e nutrientes para atender às necessidades da planta. Portanto, além de ter a capacidade volumétrica adequada, os recipientes utilizados para o cultivo de mudas devem apresentar o formato e as dimensões devidamente projetadas para as raízes se desenvolverem adequadamente. Geralmente, o maior volume do recipiente proporciona um maior desenvolvimento das raízes, propiciando uma maior exploração e absorção de água e nutrientes. Contudo, grandes dimensões de recipientes, pode acarretar em gastos desnecessários, aumento da área do viveiro, e dos custos de distribuição de mudas.

Quanto ao método de quebra de dormência, provavelmente as sementes submetidas ao método de escarificarão obtiveram maior sucesso germinativo devido ao tegumento embrionário ter ficado exposto, resultando assim um contato imediato da água com o embrião. Enquanto que no método de imersão em água fervente, o tegumento somente apresenta-se permeável a água, logo o montante de água precisa penetrar a semente até chegar ao embrião, podendo dificultar assim 0 contato da água com o embrião e por consequência sua germinação.

\section{CONCLUSÃO}

Conclui-se que mudas plantadas em recipientes de dimensões igual a 300 $\mathrm{cm}^{3}$ e submetidas ao método de superação de dormência escarificarão mecânica proporcionaram maiores altura, diâmetro de coleto, relação parte aérea e raiz e percentagem de germinação.

\section{REFERÊNCIAS}

ARALDI, D.B.; AMARAL, H.R.B. O guapuruvu. Roessleria, Porto Alegre, 1(1):109$15,1977$. 
BAO, F.; LIMA, L.B.; LUZ, P.B. Caracterização morfológica do ramo, sementes e plântulas de Matayba guianensis Aubl. e produção de mudas em diferentes recipientes e substratos. Revista Árvore, v.38, n.1, p.63-71, 2014. DOI: http://dx.doi.org/10.1590/S0100-67622014000100006

BRACHTVOGEL, E.L.; MALAVASI, U.C. Volume do recipiente, adubação e sua forma de mistura ao substrato no crescimento inicial de Peltophorum dubium (Sprengel) taubert em viveiro. Revista Árvore, v.34, n.2, p.223-232, 2010. DOI: http://dx.doi.org/10.1590/S0100-67622014000100006

BROWN, S.; LUGO, A. Rehabilitation of tropical lands: a key of sustaining development. Restoration Ecology, v.2, n.1, p.97-111, 1994. DOI: 10.1111/j.1526100X.1994.tb00047.x

CARVAlHO, P. E. R. Guapuruvu. Circular Técnica, Colombo-PR: EMBRAPA Florestas, n. 104, 2005.

COSTA, M. S.; FERREIRA, K. E. B; ; BOtOSSO, P. C.; CALLADO, C. H. Growth analysis of five Leguminosae native tree species from a seasonal semidecidual lowland forest in Brazil. Dendrochronologia, v. 36, p. 23-32, 2015. DOI: http://doi.org/10.1016/j.dendro.2015.08.004.

FERREIRA, W. C.; BOTELHO, S. A.; DAVIDE, A. C.; FARIA, J. M. R. Avaliação do crescimento do estrato arbóreo de área degradada revegetada à margem do rio grande, na Usina Hidrelétrica de Camargos, MG. Revista Árvore, v.31, n.1, p.177185, 2007. DOI: http://dx.doi.org/10.1590/S0100-67622007000100020

GARCIA, E. A.; SOUZA, J. P. Avaliação da qualidade de mudas de schizolobium parahyba em função de diferentes aplicações de adubo fosfatado. Tekhne e Logos, Botucatu, SP, v.6, n.1, p. 51-59, 2015. DOI: http://dx.doi.org/10.18188/19831471/sap.v15n4p471-475

LISBOA, A. C.; SANTOS, P. S.; OLIVEIRA; S. N.; CASTRO, D. N.; ABREU, A. H. M. A. Efeito do volume de tubetes na produção de mudas de Calophyllum brasiliense e Toona ciliata. Revista árvore, v.36, n.4, p.603-609, 2012. DOI: http://dx.doi.org/10.1590/S0100-67622012000400003.

OLIVEIRA, L. M., BRUNO, R. L. A.; SILVA, K. R. G.; SILVA, V. D. M.; FERARRI, C. S., SILVA, G. Z. Germinação e vigor de sementes de Sapindus saponaria L. submetidas a tratamentos pré-germinativos, temperaturas e substratos. Ciência Rural, v.42, n.4, p. 638-644, 2012. DOI: http://dx.doi.org/10.1590/S010384782012000400010

PEREIRA, M. O., SOUZA-LEAL, T., LAGAZZI, G., PEDROSO-DE-MORAES, C. Avaliação de métodos de escarificação na superação de dormência de Schizolobium parahyba (vell.) blake (Fabaceae caesalpinioideae). Revista em Agronegócios e Meio Ambiente, v.4, n.1, p. 119-129, 2011. ISSN 1981-9951.

SCHEER, M. B.; CARNEIRO, C.; BRESSAN, O. A.; SANTOS, K. G. Composto de ENCICLOPÉDIA BIOSFERA, Centro Científico Conhecer - Goiânia, v.14 n.25; p.496 2017 
lodo de esgoto para produção de mudas de Anadenanthera colubrina (Vell.) Brenan. Revista Cerne, Lavras, v.18, n.4, p. 613-621, $2012 . \quad$ DOI: http://dx.doi.org/10.1590/S0104-77602012000400011.

SIMÕES, D.; SILVA, R.B.G.; SILVA, M.R. Composição do substrato sobre o desenvolvimento, qualidade e custo de produção de mudas de Eucalyptus grandis hill ex maiden $\times$ Eucalyptus urophylla s. T. Blake. Ciência Florestal, v.22, n.1, p.91100, 2012. DOI: http://dx.doi.org/10.5902/198050985082 